\title{
Diabetic Nephropathy and Diabetic Kidney Disease
}

\author{
Manish Suneja \\ Department of Internal Medicine, University of Iowa Hospitals and Clinics, Iowa City, USA \\ Email: manish-suneja@uiowa.edu
}

How to cite this paper: Suneja, M. (2021) Diabetic Nephropathy and Diabetic Kidney Disease. Journal of Diabetes Mellitus, 11, 359-377.

https://doi.org/10.4236/jdm.2021.115029

Received: October 1, 2021

Accepted: November 15, 2021

Published: November 18, 2021

Copyright () 2021 by author(s) and Scientific Research Publishing Inc. This work is licensed under the Creative Commons Attribution International License (CC BY 4.0).

http://creativecommons.org/licenses/by/4.0/ (c) (i) Open Access

\begin{abstract}
Diabetic kidney disease (DKD) is the leading cause of chronic kidney disease (CKD) and end-stage kidney disease (ESKD) in the United States and worldwide. Alterations in glomerular hemodynamics, inflammation, and fibrosis are primary mediators of kidney tissue damage, although the relative contribution of these mechanisms likely varies between individuals and over the course of the natural history of diabetic kidney disease. The presence of DKD is also strongly associated with cardiovascular morbidity/mortality and has a major influence on survival. Clinical presentation and prognosis of DKD are heterogeneous and vary between individuals, although the severity of albuminuria, particularly when combined with elevated blood pressure, remains an important marker of those at higher risk of progression. Management of DKD requires a holistic approach that combines cardiovascular risk reduction with elements to slow the progression of kidney disease, namely glycemic control, RAAS inhibition and blood pressure lowering. Effective delivery of these interventions in combination reduces the risks of DKD progression, as well as other microvascular complications, cardiovascular events, and mortality. Several international groups have issued clinical guidelines that largely agree on recommended targets, and in clinical practice these should be tailored for each individual patient. SGLT2 inhibitors are exciting new options now available to slow the progression of diabetic nephropathy.
\end{abstract}

\section{Keywords}

Diabetic Kidney Disease, Diabetic Nephropathy, Chronic Kidney Disease, Proteinuria, Renin Angiotensin System

\section{Introduction}

Diabetic kidney disease and diabetic nephropathy are the leading cause of chronic kidney disease (CKD) end-stage kidney disease (ESKD) in the United States and 
worldwide. Although the prevalence of diabetes in the United States has increased over the last 20 years, the proportion of people with diabetes who also have CKD has remained relatively stable between 25 to 30 percent. Diabetes Mellitus (DM) accounts for $30 \%$ to $50 \%$ of the incident cases of end-stage kidney disease in the United States [1]. Although this represents a significant public health concern, it is important to note that only $30 \%$ to $40 \%$ of patients with diabetes develop diabetic nephropathy [2]. Diabetic kidney disease is a complex and heterogeneous disease with numerous overlapping etiologic pathways.

\section{Diabetic Nephropathys vs. Diabetic Kidney Disease}

"Diabetic nephropathy" is a diagnosis that refers to specific pathologic structural and functional changes seen in the kidneys of patients with DM (both type 1 and type 2 Diabetes Mellitus [T1/T2DM]) that result from the effects of DM on the kidney. Clinically it is characterized by persistent albuminuria and a progressive decline in renal function, and the term infers the presence of a typical pattern of glomerular disease.

"Diabetic kidney disease" (DKD) is a clinical diagnosis based upon the presence of proteinuria, decrease estimated glomerular filtration rate (eGFR), or both in diabetes. It does not indicate a specific pathological type. It can be from many diverse causes, including hypertensive nephrosclerosis and unresolved acute kidney failure. The likelihood that "diabetic nephropathy" is the cause of diabetic kidney disease varies widely depending upon the clinical circumstances. It is highly likely that diabetic nephropathy is the cause of diabetic kidney disease in type 1 diabetes of five or more years duration with albuminuria, but the frequency can range widely in type 2 diabetes.

\subsection{Epidemiology}

The risk for the development of diabetic nephropathy has a genetic component that is likely polygenetic. The prevalence of diabetic nephropathy varies among racial and ethnic groups such that African Americans, Native Americans, and Mexican Americans have increased risk as compared with European Americans. The disparity in DKD disease among minority populations could also be explained in large part by socioeconomic status, which is tightly intertwined with educational attainment. Albuminuria and decreased eGFR $\left(<60 \mathrm{~mL} / \mathrm{min} / 1.72 \mathrm{~m}^{2}\right)$ is more common among individuals with lower education level, even after controlling for sociodemographic and clinical factors [3]. Although an argument can be made that barriers to care are a major contributor to this discrepancy in prevalence, it is likely not the sole factor, and genetic differences potentially also play a role. The apolipoprotein 1 (APOL1) gene has been found to explain some of the racial disparity in nondiabetic ESKD but it has not born out as a causative factor for diabetic kidney disease among African Americans. However, APOL1 variants are associated with an increased risk for progression of diabetic kidney disease in African Americans [4]. Familial studies have also demonstrated clus- 
tering of diabetic nephropathy. Patients with DM with a first-degree relative with T1/T2DM and diabetic nephropathy have substantially more risk for developing diabetic nephropathy than those without an affected relative. This familial clustering has also been well documented in the Pima Indian population [5]. Ongoing efforts to identify specific genetic factors and genes associated with the development of diabetic nephropathy are ongoing. Several candidate genes, including glucose transporter 2 , transforming growth factor $\beta$, and endothelial nitric oxide synthase, have been identified, isolating a definitive causal pathway has proved to be elusive because there is no simple mendelian inheritance, and the interplay of several genes is likely involved and may differ between populations.

\subsection{Pathophysiology}

Hyperglycemia results in production of advanced glycation end-products (AGE) and reactive oxygen species [6]. While hyperglycemia undoubtedly plays a central role, hyperinsulinemia and insulin resistance also may incite pathogenic mechanisms, possibly accounting for variation in histopathology between type 1 and type 2 diabetes. Ultimately, alterations in glomerular hemodynamics, inflammation, and fibrosis are primary mediators of kidney tissue damage, although the relative contribution of these mechanisms likely varies between individuals and over the course of the natural history of diabetic kidney disease [7] [8].

The pathophysiology leading to the development of diabetic nephropathy and resultant end-stage kidney disease follows from the diabetic milieu leading to the generation and circulation of advanced glycation end products, elaboration of growth factors, and hemodynamic and hormonal changes. These lead to the release of reactive oxygen species and inflammatory mediators. Collectively, these changes result in glomerular hyperfiltration, glomerular hypertension, renal hypertrophy, and altered glomerular composition, which is manifested clinically as albuminuria and hypertension [9]. Pathologically, the kidneys undergo several changes, including deposition (in primarily the mycangium) of extracellular matrix, glomerular basement membrane thickening, proliferative changes, and tubular atrophy, ultimately resulting in interstitial fibrosis and glomerulosclerosis (the final common pathway of many kidney diseases).

With the onset of DM, kidney size and weight increase by an average of $15 \%$, and this size increase remains even after progressive reductions in kidney function occur. An examination of kidney tissue reveals thickening of the glomerular basement membrane and expansion of the mesangium. The classic pathologic lesion of diabetic nephropathy is nodular in nature and was first described by Kimmelstiel and Wilson in 1936. The nodules are typically acellular and positive by periodic acid-Schiff stain. Although these nodules are pathognomonic for diabetic nephropathy, they are reported in only $10 \%$ to $50 \%$ of biopsy specimens from patients with T1/T2DM [9]. Far more common is the diffuse glomerular 
lesion that is characterized by diffuse mesangial matrix expansion. Arteriolar lesions involving both the afferent and efferent vessels are also prominent and common in DM. Over time, hyaline material replaces the entire vessel wall structure, and this is highly specific for DM [10].

\subsection{Natural History of Diabetic Nephropathy}

The natural history of diabetic nephropathy in patients with T1DM was initially characterized in patients with juvenile-onset DM in the late 1970s by examining death records of patients who were classified as having died of kidney failure. This study helped us understand the true untreated natural history of diabetic nephropathy due to T1DM as it was before the advent of therapy for diabetic nephropathy [11]. Based on this study, proteinuria appears 11 to 23 years after the T1DM diagnosis, serum creatinine concentration begins to increase after 13 to 25 years, and ESKD develops after 18 to 30 years. With the subsequent development of more sensitive assays to detect urinary albumin excretion, small amounts of albumin in the urine were noted to precede the development of overt proteinuria in most patients, occurring 5 to 10 years after the diagnosis of DM [12].

Presently, microalbuminuria and macroalbuminuria are referred to as A2 and A3, respectively (Table 1), by the KDIGO (Kidney Disease: Improving Global Outcomes) chronic kidney disease (CKD) guideline [13]. The natural history of diabetic nephropathy in patients in longitudinally studied populations with T2DM is essentially identical to that in patients with T1DM, though the timing of diabetes onset in patients with T2DM is difficult to assess. Therefore, a patient may even present with proteinuria and on kidney biopsy have diabetic nephropathy before T2DM is diagnosed. Another important difference in the natural history of patients with $\mathrm{T} 1$ versus $\mathrm{T} 2 \mathrm{DM}$ is that the major macrovascular complication, namely cardiac disease and death due to cardiac disease, can occur at any point along the course of a patient with T2DM from the onset of DM and early diabetic nephropathy, whereas the elevated risk for cardiovascular disease is not apparent until advanced kidney disease has developed in patients with T1DM [14].

The classic study by Kussman et al in patients with T1DM allows one to picture a timeline of kidney disease progression that starts with microalbuminuria and proceeds sequentially through stages of overt proteinuria, kidney function decline, and ultimately end-stage kidney disease [11]. Multiple studies of diabetic nephropathy progression over the years have confirmed this timeline and the critical role of proteinuria assessment both as a diagnostic criterion for the presence of diabetic nephropathy and for the assessment of disease severity and likelihood of progression. The single biggest predictor of kidney function deterioration and diabetic nephropathy progression is proteinuria [15]. When the loss of kidney function has begun, as evidenced by an increasing serum creatinine concentration or a declining estimated glomerular filtration rate (eGFR), the 
Table 1. KDIGO definitions of albuminuria category.

\begin{tabular}{cccc}
\hline \multicolumn{4}{c}{ Urinary albumin categories } \\
\hline Measure & Normal or mildly increased (A1) & \\
\hline Albumin excretion rate $(\mathrm{mg}$ per $24 \mathrm{~h})$ & $<30$ & $30-300$ & $>300$ \\
Albumin-to-creatinine ratio $(\mathrm{mg} / \mathrm{g})$ & $<30$ & $30-300$ & $>300$ \\
Albumin-to-creatinine ratio $(\mathrm{mg} / \mathrm{mmol})$ & $<3$ & $3-30$ & $>30$
\end{tabular}

patient with diabetic nephropathy begins a continual decline toward chronic kidney disease and renal replacement therapy or death. Based on studies of untreated patients with T1DM and Pima Indians with T2DM, the rate of GFR loss can be on the order of 7 to $12 \mathrm{~mL} / \mathrm{min} / 1.73 \mathrm{~m}^{2}$ per year. Treatment with renin-angiotensin system (RAS) inhibitors has reduced this rate of decline to 3 to 6 $\mathrm{mL} / \mathrm{min} / 1.73 \mathrm{~m}^{2}$ per year [5].

Recent reports have noted that up to $25 \%$ of patients with T2DM and diminished kidney function have little or no proteinuria despite having biopsy-proven diabetic nephropathy [16].

The cause of this change in profile of diabetic nephropathy is unclear. This phenomenon may be due to the impact of long-term RAS-inhibitor therapy, underdiagnosed unresolved acute kidney injury, or other factors impacting on the traditional natural history described earlier.

\section{Clinical Approach to Diagnosis of Diabetic Nephropathy}

In many cases, Nephropathy is a clinical diagnosis. A kidney biopsy is the gold standard test for diagnostic and prognostic information, but in most centers is usually only performed when an alternative renal pathology is suspected.

\subsection{Screening}

DKD usually does not cause symptoms, so guidelines from the ADA and KDIGO group recommend that kidney function and albuminuria should be measured at diagnosis and annually thereafter in T2DM and in type $1 \mathrm{DM}$ recommendation is to start screening from 5 years after diagnosis [13] [17]. Albuminuria is best assessed using ACR measurements on spot urine samples (ideally early morning samples); timed or 24-hour urine collections to measure albumin excretion are also appropriate although less convenient and more prone to collection errors. Renal function should be assessed using a serum-creatinine based eGFR calculation (CKD-EPI equation recommended due to its superior performance in the eGFR range $60-90 \mathrm{~mL} / \mathrm{min} / 1.73 \mathrm{~m}^{2}$ ).

\subsection{Confirmation of Persistent Abnormalities}

If a reduction in eGFR or an increase in albuminuria is detected, this should be confirmed on repeat testing over 3 to 6 months; a minimum of two elevated ACR levels more than 3 months apart are required before an individual is con- 
sidered to have increased albuminuria [13]. This is to differentiate from transient changes as well as to account for the intra-individual variation that is seen in ACR. Similarly, two eGFR values below $60 \mathrm{~mL} / \mathrm{min} / 1.73 \mathrm{~m}^{2}$ at least 90 days apart are required to make a diagnosis of CKD.

\subsection{Diagnosis of Diabetic Nephropathy}

The approach to a patient with DM and evidence of kidney disease must center on the determination of whether the patient's kidney disease is diabetic nephropathy or another kidney disease. The natural history and progression timeline discussed earlier will greatly aid the clinician in determining the likelihood that a given patient's disease is diabetic nephropathy in individuals with T1DM [10]. The development of significant albuminuria before 5 years' or after 25 years' duration of T1DM decreases the likelihood of diabetic nephropathy [11]. Additionally, 95\% of patients with T1DM and diabetic nephropathy also have diabetic retinopathy, so the absence of retinopathy may imply a diagnosis other than diabetic nephropathy [18]. Seven-field fundus photos must be obtained to eliminate the presence of retinopathy and prompt kidney biopsy because a dilated ophthalmologic examination is insensitive. In T1DM, a clinical diagnosis of DKD can be made when there is persistent moderate (A2) or severe (A3) albuminuria or a persistent reduction in eGFR to $<60 \mathrm{~mL} / \mathrm{min} / 1.73 \mathrm{~m}^{2}$, occurring at least 5 years after onset of diabetes. In over $95 \%$ of cases, diabetic retinopathy will also be present, and there should be no clinical suggestions of alternative kidney disease. Albuminuria is not required to make a diagnosis of DKD in the setting of a persistently reduced eGFR, but this clinical scenario should prompt consideration of other forms of non-albuminuric kidney disease, as should albuminuria in the absence of retinopathy.

Diagnosis of $\mathrm{DN}$ in patients with $\mathrm{T} 2 \mathrm{DM}$ is more challenging because these epidemiologic clues are not as helpful. Diabetic retinopathy is concordant with diabetic nephropathy in only about $60 \%$ to $65 \%$ of cases; thus, its absence does not generate a high negative predictive value for the diagnosis of diabetic nephropathy [19]. Also, because the onset of T2DM is generally unknown, one cannot as reliably use the natural history timeline to assist in diagnosis [20]. Thus, it is really important to assess whether something other than DM is the cause of kidney disease. This evaluation will typically involve a thorough history and physical examination and selected laboratory and imaging tests to determine whether a kidney biopsy would be of benefit. There is no formal practice guideline on when to pursue kidney biopsy in patients with DM. Prospective kidney biopsy studies have illustrated that if a patient with DM has retinopathy (T1DM), onset of proteinuria in the usual timeframe (T1DM), and no evidence to support another disease (T1/T2DM), an alternative diagnosis that would substantially alter therapy is unlikely to be found [18]. Therefore, it is not surprising that most patients with DM and reduced kidney function do not undergo kidney biopsy. In T2DM, the clinical diagnosis can be more challenging due to the in- 
creased heterogeneity of clinical presentation, although the same principles of persistent albuminuria or persistently reduced eGFR apply. Again, albuminuria does not have to be present to make a diagnosis of DKD providing eGFR is persistently $<60 \mathrm{~mL} / \mathrm{min} / 1.73 \mathrm{~m}^{2}$. Longer duration of diabetes and presence of retinopathy are important pointers towards the diagnosis when they are present, but neither a short duration of diabetes nor absence of retinopathy are useful to rule out DKD in T2DM. It is therefore important to evaluate for features that may indicate alternative forms of kidney disease and proceed to renal biopsy when there is diagnostic uncertainty.

\section{Features That May Indicate Alternative Forms of Kidney Disease}

Non-diabetic forms of kidney disease may be suggested by the following:

1) Atypical trajectory of eGFR decline or onset of albuminuria. Rapid declines in eGFR ( $>5 \mathrm{~mL} / \mathrm{min} /$ year) or sudden onset of albuminuria are not typical of $\mathrm{DN}$, nor is severe albuminuria in the first 5 years of T1DM. Looking at serial eGFR trends will help to identify previous episodes of AKI, which are increasingly recognized to be associated with CKD onset and progression [21] [22].

2) Very severe albuminuria (ACR $>300 \mathrm{mg} / \mathrm{mmol}$ or $>3000 \mathrm{mg} / \mathrm{g}$ ) or nephrotic syndrome. Although DN is a well-recognized cause of nephrotic syndrome, primary glomerular disease is more likely in this setting, particularly when the nephrotic syndrome has an acute onset.

3) Active urinary sediment. Microscopic hematuria is not a classical finding in DN but can occur. The presence of hematuria on urinalysis is not particularly helpful and has poor ability to discriminate between diabetic and non-diabetic kidney disease [23]. However, the presence of red cell casts or dysmorphic red cells on urine microscopy is much more likely to signify an alternative pathology, typically a glomerulonephritis.

4) Diagnosis of or clinical features that are suspicious for another systemic disease that commonly causes kidney disease (e.g., connective tissue disorders, HIV).

5) Family history of non-diabetic forms of kidney disease.

\section{Differential Diagnoses to Consider in the Setting of Non-Albuminuric DKD}

Although non-albuminuric DN is well described, this presentation should prompt evaluation for the following:

1) Ischemic nephropathy. Suggested by vascular disease elsewhere, smoking history, hypertension, aortic disease, or asymmetric kidneys on renal ultrasound. Sometimes, this scenario is incorporated under the umbrella term of DKD (i.e., without renal biopsy), and several of the risk factors for ischemic nephropathy are very common in people with diabetes. Renovascular disease can also be suggested by large (>30\%) declines in eGFR after initiation of RAAS inhibitors. 
2) Dysproteinemia-related renal disease. There are a variety of renal diseases associated with dysproteinemias that are initially screened for with serum electrophoresis and assay of serum free light chains. This includes monoclonal gammopathy of renal significance, defined as a clonal proliferative disorder that produces a nephrotoxic monoclonal immunoglobulin, but does not meet the treatment criteria for a specific hematological malignancy [24].

3) Previous episodes of AKI.

4) Tubulointerstitial nephritis (TIN), classically associated with eosinophilia and urinary leukocytes but can present with normal urinary sediment. TIN is often due to medications (e.g., non-steroidal anti-inflammatory drugs, proton-pump inhibitors, antibiotics, diuretics), and a careful medication history to establish temporal links between initiation of culprit medications and onset of eGFR decline can be useful. Diagnosis requires kidney biopsy.

\section{Treatment of Diabetic Nephropathy}

Specific treatment of patients with diabetic nephropathy can be divided into 4 major arenas: cardiovascular risk reduction, glycemic control, BP control, and inhibition of the RAS and emerging therapies including SGLT-2 inhibitors. Each of these arenas will be discussed with a focus on an optimal evidence-based approach to care of patients with diabetic nephropathy.

\subsection{Cardiovascular Risk Reduction}

Patients with diabetic nephropathy necessarily have DM and thus cardiovascular disease risk is significant and a competing risk for kidney failure. Therefore, it is important to ensure that aggressive risk factor modification is undertaken, usually in partnership with the patient's primary care physician. Components of this therapeutic approach include tobacco cessation and lipid-lowering therapy. Evidence of cardiovascular disease risk reduction for both tobacco cessation and lipid lowering is abundant though, it is outside the scope of this review.

\subsection{Glycemic Control}

The effect of improved glycemic control on clinical outcomes, including progression of diabetic nephropathy, has been tested in multiple large clinical trials involving patients with T1/T2DM. The principal evidence regarding the benefit of glycemic control in patients with T1DM comes from the Diabetes Control and Complications Trial (DCCT) [25]. This seminal trial, conducted from 1983 to 1993 in the United States and Canada, randomly assigned 1441 patients to intensive (goal $\mathrm{HbA}_{1 \mathrm{c}}<6.05 \%$ ) versus conventional glycemic control with insulin with follow-up for a mean of 6.5 years. Median $\mathrm{HbA}_{1 \mathrm{c}}$ concentration was $9.1 \%$ versus $7.3 \%$ for conventional versus intensive control. Intensive control resulted in a relative risk reduction of $39 \%$ for the development of microalbuminuria and relative risk reduction of $56 \%$ for overt proteinuria. Intensive glycemic control was also associated with reductions in other microvascular complications, namely 
retinopathy and neuropathy. After the trial ended, 1375 participants volunteered to continue in the Epidemiology of Diabetes Interventions and Complications (EDIC) Study [26]. Given the benefits seen with the intensive control arm in the DCCT, all participants were advised to remain or convert to intensive control. Thus, glycemic control as measured by $\mathrm{HbA}_{1 \mathrm{c}}$ concentration converged to $7.8 \%$ and $7.9 \%$ for the former conventional and former intensive control groups, respectively. Despite this convergence, the development of microalbuminuria and overt proteinuria was reduced ( $53 \%$ and $86 \%$, respectively) by intensive control over 4 additional years of follow-up. Thus, the beneficial effects of glycemic control on microvascular complications are significant and durable in patients with T1DM.

The available data for patients with T2DM are more ambiguous. In the United Kingdom Prospective Diabetes Study (UKPDS), participants were randomly assigned to intensive glycemic control using oral agents and/or insulin or to conventional therapy (diet control) [27]. The achieved mean $\mathrm{HbA}_{1 c}$ concentration was $7.0 \%$ in the intensive control arm compared to $7.9 \%$ in the conventional arm. Participants in the intensive control arm saw a reduction in any DM-related end point, but a reduction was not seen for specific kidney events of interest, namely the development of microalbuminuria, overt proteinuria, or doubling of serum creatinine concentration. Three more recent large trials with an aggregate enrollment of nearly 25,000 participants were conducted to assess any potential benefit of intensive glucose control in T2DM: ADVANCE (Action in Diabetes and Vascular Disease), ACCORD (Action to Control Cardiovascular Risk in Diabetes), and VADT (VA Diabetes Trial) [28] [29] [30]. These studies targeted and achieved $\mathrm{HbA}_{1 \mathrm{c}}$ concentrations of $\sim 6.0 \%$ relative to a control arm of $\sim 7.0 \%$. Results of these studies are decidedly mixed, with either no benefits on cardiovascular effects ranging to cardiovascular risk in the intensive group and no kidney benefit, with the exception of 1 trial showing a reduction in albuminuria but no benefit on the preservation of kidney function. All 3 trials established increased risk for hypoglycemic events related to intensive glycemic control to $\mathrm{HbA}_{1 \mathrm{c}}$ concentrations of near $6.0 \%$. Intensive glycemic control to an $\mathrm{HbA}_{1 \mathrm{c}}$ concentration of $7.0 \%$ prevents microvascular (not macrovascular) complications (UKPDS). However, it is unclear whether any further $\mathrm{HbA}_{1 c}$ concentration reduction is of utility, particularly for preventing kidney disease outcomes.

Based on the available evidence (Table 2), target goal $\mathrm{HbA}_{1 c}$ concentration should be close to $7.0 \%$ to reduce microvascular complications and diabetic nephropathy progression. Any further reduction is of unproven benefit and would likely put the patient at risk for hypoglycemic events. This is congruent with current American Diabetes Association and KDOQI clinical practice guidelines.

\subsection{Blood Pressure Control}

Hypertension has been linked to the development of microalbuminuria, overt 
Table 2. Summary of key glycemic control trials.

\begin{tabular}{|c|c|c|c|c|c|c|}
\hline Trial & Population & $\mathbf{N}$ & $\begin{array}{l}\text { Intervention } \\
\text { Target }\end{array}$ & $\begin{array}{l}\text { Achieved } \\
\text { Intervention }\end{array}$ & $\begin{array}{l}\text { Findings in Intensive } \\
\text { Care Group }\end{array}$ & Comments \\
\hline DCCT & T1DM & 1441 & $\begin{array}{l}\text { Intensive therapy } \\
\text { targeting fasting and } \\
\text { postprandial blood } \\
\text { glucose vs. } \\
\text { conventional therapy }\end{array}$ & $\begin{array}{l}\mathrm{HbA}_{1 \mathrm{c}} 7.3 \% \\
\text { vs. } 9.1 \%\end{array}$ & $\begin{array}{l}\text { Decreased } \\
\text { microvascular } \\
\text { complications } \\
\text { (including } \\
\text { microalbuminuria, } \\
\text { proteinuria, retinopathy, } \\
\text { and neuropathy) }\end{array}$ & \\
\hline EDIC & T1DM & $\begin{array}{l}1375 \text { patients } \\
\text { that completed } \\
\text { DCCT }\end{array}$ & $\begin{array}{l}\text { Observational } \\
\text { follow-up of DCCT } \\
\text { with all getting } \\
\text { intensive therapy }\end{array}$ & $\begin{array}{l}\mathrm{HbA}_{1 \mathrm{c}} 7.8 \% \\
\text { vs. } 7.9 \%\end{array}$ & $\begin{array}{l}\text { Reduction in } \\
\text { microalbuminuria and } \\
\text { proteinuria }\end{array}$ & \\
\hline UKPDS & $\begin{array}{l}\text { Newly } \\
\text { Diagnosed } \\
\text { T2DM }\end{array}$ & 3867 & $\begin{array}{l}\text { Intensive therapy } \\
\text { targeting a fasting } \\
\text { blood glucose vs. } \\
\text { conventional therapy }\end{array}$ & $\begin{array}{l}\mathrm{HbA}_{1 \mathrm{c}} 7 \% \\
\text { vs. } 7.9 \%\end{array}$ & $\begin{array}{l}\text { Reduction in any } \\
\text { diabetes-related end } \\
\text { point in aggregate }\end{array}$ & $\begin{array}{l}\text { Reduction not seen in } \\
\text { kidney-specific events } \\
\text { (microalbuminuria, } \\
\text { proteinuria, or } \\
\text { doubling of Scr) }\end{array}$ \\
\hline ACCORD & $\begin{array}{l}\text { T2DM and CV } \\
\text { event history } \\
\text { or risk }\end{array}$ & 10,251 & $\begin{array}{l}\mathrm{HbA}_{1 \mathrm{c}}<6.0 \% \\
\text { vs. } 7 \%-7.9 \%\end{array}$ & $\begin{array}{l}\mathrm{HbA}_{1 \mathrm{c}} 6.4 \% \\
\text { vs. } 7.5 \%\end{array}$ & $\begin{array}{l}\text { Increased CV and total } \\
\text { mortality }\end{array}$ & $\begin{array}{l}\text { No benefit on kidney } \\
\text { end points }\end{array}$ \\
\hline ADVANCE & $\begin{array}{l}\text { T2DM and CV } \\
\text { event history } \\
\text { or risk }\end{array}$ & 11,140 & $\begin{array}{l}\mathrm{HbA}_{1 \mathrm{c}}<6.5 \% \\
\text { vs. routine care }\end{array}$ & $\begin{array}{l}\mathrm{HbA}_{1 \mathrm{c}} 6.3 \% \\
\text { vs. } 7.0 \%\end{array}$ & $\begin{array}{l}\text { No benefit on CV } \\
\text { outcomes; reduction in } \\
\text { microvascular events }\end{array}$ & $\begin{array}{l}\text { Albuminuria reduced } \\
\text { by } 21 \%\end{array}$ \\
\hline VADT & $\begin{array}{l}\text { T2DM and } \\
\text { poor BP } \\
\text { control }\end{array}$ & 1791 & $\begin{array}{l}\text { Reduction in } \mathrm{HbA}_{1 \mathrm{c}} \\
\text { of } 1.5 \% \text { vs. routine } \\
\text { care }\end{array}$ & $\begin{array}{l}\mathrm{HbA}_{1 \mathrm{c}} 6.9 \% \\
\text { vs. } 8.4 \%\end{array}$ & No benefit & $\begin{array}{l}\text { No benefit on kidney } \\
\text { end points }\end{array}$ \\
\hline
\end{tabular}

proteinuria, and declining kidney function, with higher BP associated with worse outcomes in a continuous fashion [31]. Two randomized trials in T2DM, IDNT (Irbesartan Diabetic Nephropathy Trial) and the RENAAL (Reduction in Endpoints in Non-Insulin Dependent Diabetes Mellitus with the Angiotensin II Antagonist Losartan) demonstrated benefit of angiotensin receptor blockers (ARBs) in delaying the progression of kidney disease [6] [15]. However, the participants in these 2 trials were not randomly assigned to different levels of $\mathrm{BP}$ control. Analyses of both these studies revealed that participants with poor BP control at entry did worse relative to their better-controlled counterparts. These studies also noted that achieved BP was a stronger predictor of kidney outcome than entry BP. Achieved BPs and its effect was analyzed in detail in IDNT and revealed a J-shaped curve such that kidney benefit reached a plateau at systolic $\mathrm{BP}<130 \mathrm{~mm} \mathrm{Hg}$, and at systolic BP $<120 \mathrm{~mm} \mathrm{Hg}$, all-cause mortality started increasing.

UKPDS was one of the studies which randomly assigning participants to 2 different levels of BP control. This study examined the impact of 2 different levels of BP control on microvascular and macrovascular complications [32]. Dur- 
ing a mean 8.4 years of follow-up, achieved mean BPs in the 2 groups were 144/82 versus 154/87mm Hg. The risk for any DM-related complication, death, adverse cardiovascular events, and the composite of microvascular events was substantially decreased in the lower BP arm. The study did not demonstrate benefit on the kidney outcomes (proteinuria and kidney function decline), though it was not specifically designed to assess kidney outcomes. The benefits of BP control below a systolic BP of $140 \mathrm{~mm} \mathrm{Hg}$ have been more difficult to demonstrate. The ABCD (Appropriate Blood Pressure in Diabetes) trial randomly assigned participants with T2DM to intensive (achieved BP $\sim 128 / 75 \mathrm{~mm} \mathrm{Hg}$ ) versus moderate (achieved BP $\sim 137 / 81 \mathrm{~mm} \mathrm{Hg}$ ) control with follow-up for 5 years. The study noted a decrease in the development of microalbuminuria and overt proteinuria in the intensive BP group, but was unable to demonstrate a benefit on creatinine clearance, the primary outcome of the trial [33].

The ACCORD trial tested the hypothesis that more intensive BP control (systolic BP $<120 \mathrm{~mm} \mathrm{Hg}$ ) would be of benefit relative to standard BP therapy (systolic $\mathrm{BP}<140 \mathrm{~mm} \mathrm{Hg}$ ), with 4733 patients participating in this randomized trial [34]. The achieved systolic BPs at 1 year of follow-up were widely separated, at $119.3-$ and $133.5-\mathrm{mm} \mathrm{Hg}$ in the 2 groups. It took on average $3.5 \mathrm{BP}$ medications to achieve this $\mathrm{BP}$ goal in the intensive therapy group versus $2.3 \mathrm{BP}$ medications in the standard therapy group. The study found no reduction in the rate of the primary composite cardiovascular outcome associated with either BP goal. Intensive BP control was associated with a reduction in albuminuria, but no reduction was seen in end-stage kidney disease events. ACCORD trial was not powered to detect renal events because the trial population was a more general cohort with DM rather than one selected for diabetic kidney disease. Increased risk for acute kidney injury events requiring dialysis therapy along with other adverse events attributed to antihypertensive therapy were also seen in the intensive BP control arm.

Based on the current evidence, it is clear that BP reduction is important in the management of patients with diabetic nephropathy [35]. Cardiovascular and kidney event rates are higher with increasing $\mathrm{BP}$ and are reduced progressively with therapy to lower BP. There may be a point beyond which further BP reduction may not be helpful or even be harmful despite a reduction in proteinuria [36].

\subsection{RAS Inhibition}

RAS blockade using various drugs, including ACE inhibitors, ARBs, direct renin inhibitors, and mineralocorticoid antagonists have shown efficacy in animal models of diabetic nephropathy across the full spectrum of DM-related injury. In humans, RAS inhibition has proved to be the single most effective therapy for slowing the progression of diabetic nephropathy. These agents have been studied at each clinical stage of diabetic nephropathy, and we review those data here.

RAS blockade has been studied in patients with T1/T2DM without microalbuminuria to assess whether therapy can prevent its development. Multiple trials 
in patients with T1DM suggest that early therapy in T1DM is ineffective in preventing the development of microalbuminuria. This treatment strategy has also been tested in patients with T2DM with mixed results. The ROADMAP (Randomized Olmesartan and Diabetes Microalbuminuria Prevention) trial followed up 4449 participants with T2DM for a median of 3.2 years. There was a statistically significant follow-up difference in BP between the olmesartan and placebo arms. The primary analysis of the trial showed that olmesartan prevented or delayed the onset of microalbuminuria, with microalbuminuria developing in $8.2 \%$ versus $9.8 \%$ of participants (olmesartan vs. placebo) [37]. The olmesartan group had lower BPs and an increase in cardiovascular deaths. Thus, RAS blockade may prevent the development of microalbuminuria in patients with T2DM.

The next group of studies looked at the timeline of the transition of a patient with microalbuminuria to overt proteinuria. Treatment with the ARB irbesartan was investigated for its ability to prevent the development of overt proteinuria in patients with T2DM and microalbuminuria in the IRMA-2 (Effect of Irbesartan in the Development of Diabetic Nephropathy in Patients with T2DM) trial [38]. This trial randomly assigned 590 patients with T2DM and microalbuminuria to irbesartan, $150 \mathrm{mg}$, daily; irbesartan, $300 \mathrm{mg}$, daily; or matching placebo with follow-up for 2 years. Irbesartan reduced the risk for the development of overt proteinuria (defined here as albumin excretion $>200 \mathrm{mg} / \mathrm{d}$ ) in the intent-to-treat group as a whole. Examining the subgroups, a dose-dependent benefit was suggested, with hazard ratios (HRs) of $0.3(P<0.001)$ in 300-mg group and $0.61(P$ $=0.08)$ in the $150-\mathrm{mg}$ group.

The first major trial which examined the effect of ACE inhibitors on the progression of advanced diabetic nephropathy randomly assigned 409 patients with T1DM, overt proteinuria (protein excretion $\geq 500 \mathrm{mg} / \mathrm{d}$ ), and reduced kidney function (serum creatinine $\leq 2.5 \mathrm{mg} / \mathrm{dL}$ ) to captopril, $25 \mathrm{mg}$, 3 times a day or matching placebo [39]. Participants in this trial could receive other antihypertensive medications to achieve BP control. There was a $48 \%$ reduction in risk for doubling of serum creatinine concentration and a 50\% reduction in the composite end point of death, dialysis therapy, or transplantation. This trial established the efficacy of ACE inhibitors independent of BP control in slowing the progression of diabetic nephropathy in patients with T1DM and overt proteinuria.

IDNT and the RENAAL study investigated the effect of 2 ARBs (irbesartan and losartan, respectively) on the progression of diabetic nephropathy in patients with T2DM, overt proteinuria, and reduced kidney function [40] [41]. IDNT randomly assigned 1715 participants to irbesartan, amlodipine, or placebo with follow-up for a mean of 2.6 years. BP was targeted at $<135 / 85 \mathrm{~mm} \mathrm{Hg}$ and was achieved with agents in classes other than those under study [41]. Independent of BP control, irbesartan reduced the risk for the composite outcome of doubling of serum creatinine concentration, end-stage kidney disease, or death as compared to amlodipine or placebo. The RENAAL trial followed up $1513 \mathrm{pa}$ tients with T2DM and overt proteinuria for a mean of 3.4 years and demon- 
strated that losartan, $100 \mathrm{mg}$, daily was superior to placebo to reduce the risk for the same composite end point as in IDNT [40]. Taken together, these studies provide robust evidence supporting the benefit independent of BP control of RAS-blocking medication on slowing the progression of diabetic nephropathy. Although these trials showed a dramatic benefit with ARB therapy, many participants on ARB therapy still had renal events, which raised the question for trials to assess further therapy and drug development to derive further benefit.

The question of therapy with multiple agents that block the RAS was addressed in 3 large clinical trials. The first was ONTARGET (Ongoing Telmisar$\tan$ Alone and in Combination with Ramipril Global Endpoint), a cardiovascular outcomes trial that randomly assigned 25,620 patients with cardiovascular disease risk to ramipril, telmisartan, or both. There was no difference among the 3 arms in the composite cardiovascular outcome [42]. Notably, there were 9612 participants with diabetes and 2781 with microalbuminuria in the trial. Post hoc analysis of kidney outcomes showed a proteinuria benefit in the combination therapy arm. However, there was a significant increase in the renal end point (doubling of serum creatinine, dialysis therapy, or death) in the combination therapy arm compared with the single-agent arms. This increase in the renal end point was primarily driven by the need for urgent dialysis. Although not designed as a kidney outcomes trial, this raised questions about the potential harm of combination therapy. The VA NEPHRON-D (Veterans Affairs Nephropathy in Diabetes) study randomly assigned 1448 participants with T2DM and overt proteinuria to either losartan, $100 \mathrm{mg}$, daily in combination with lisinopril, 40 $\mathrm{mg}$, daily or losartan, $100 \mathrm{mg}$, daily plus placebo. This trial was terminated early due to an increase in adverse events (acute kidney injury and hyperkalemia) in the combination therapy arm [43]. ALTITUDE (Aliskiren Trial in T2DM Using Cardio-Renal Endpoints) tested whether dual RAS blockade with Aliskiren and either an ACE inhibitor or an ARB reduced cardiovascular and kidney events. This trial was also terminated early due to an increase in adverse events and no apparent benefit in the dual-therapy group [44].

The current evidence (Table 3) strongly supports the use of RAS-blocking agents in the treatment of patients with diabetic nephropathy. Although RAS blockade with more than 1 agent may be effective in reducing proteinuria, the adverse-event profile (hyperkalemia, acute kidney injury, and increased cardiovascular events) and the lack of benefit in preventing end-stage kidney disease preclude its general use for the treatment of diabetic nephropathy.

\subsection{Emerging Therapies}

Sodium glucose cotransporter 2 (SGLT2) inhibitors are relatively new medications that have been approved for the treatment of diabetes. Their mechanism of action is to block glucose and sodium uptake in the proximal tubule, thereby generating natriuresis and glucosuria [45]. Two studies designed as cardiovascular safety studies, EMPA-REG Outcome (Empagliflozin, Cardiovascular Outcomes, 
Table 3. Summary of key renin-angiotensin system inhibition trials.

\begin{tabular}{|c|c|c|c|c|c|}
\hline Trial & Population & $\mathbf{N}$ & Intervention & Conclusions & Comments \\
\hline ROADMAP & $\begin{array}{l}\text { T2DM without } \\
\text { microalbuminuria }\end{array}$ & 4449 & Olmesartan vs. placebo & $\begin{array}{l}\text { Olmesartan delayed the onset of } \\
\text { microalbuminuria }\end{array}$ & $\begin{array}{l}\text { Olmesartan group had } \\
\text { lower BPs and more } \\
\text { CV deaths }\end{array}$ \\
\hline IRMA-2 & $\begin{array}{l}\mathrm{T} 2 \mathrm{DM} \text { and } \\
\text { microalbuminuria }\end{array}$ & 590 & $\begin{array}{l}\text { Irbesartan } 150 \mathrm{mg} \\
\text { vs. irbesartan } 300 \mathrm{mg} \\
\text { vs. placebo }\end{array}$ & $\begin{array}{l}\text { Irbesartan reduced the } \\
\text { development of overt proteinuria }\end{array}$ & $\begin{array}{l}\text { Subgroup analysis } \\
\text { suggested a } \\
\text { dose-dependent effect }\end{array}$ \\
\hline $\begin{array}{l}\text { Captopril } \\
\text { Trial }\end{array}$ & $\begin{array}{l}\text { T1DM with } \\
\text { proteinuria }\end{array}$ & 409 & $\begin{array}{l}\text { Captopril } 25 \mathrm{mg} 3 \times / \mathrm{d} \text { vs. } \\
\text { placebo }\end{array}$ & $\begin{array}{l}\text { Captopril reduced the risk for } \\
\text { doubling of SCr as a primary } \\
\text { outcome and death, dialysis } \\
\text { therapy, or transplantation as a } \\
\text { secondary outcome }\end{array}$ & \\
\hline IDNT & $\begin{array}{l}\text { T2DM with } \\
\text { proteinuria and } \\
\text { reduced kidney } \\
\text { function }\end{array}$ & 1715 & $\begin{array}{l}\text { Irbesartan vs. amlodipine } \\
\text { vs. placebo }\end{array}$ & $\begin{array}{l}\text { eIrbesartan reduced the risk for } \\
\text { doubling of SCr, ESRD, or death }\end{array}$ & \\
\hline RENAAL & $\begin{array}{l}\text { T2DM with } \\
\text { proteinuria and } \\
\text { reduced kidney } \\
\text { function }\end{array}$ & 1513 & Losartan vs. placebo & $\begin{array}{l}\text { Losartan reduced the risk for } \\
\text { doubling of SCr, ESRD, or death }\end{array}$ & \\
\hline ONTARGET & $\begin{array}{l}\text { Patients with } \mathrm{CV} \\
\text { risk }\end{array}$ & 25,620 & $\begin{array}{l}\text { Ramipril vs. telmisartan } \\
\text { vs. telmisartan and } \\
\text { ramipril }\end{array}$ & $\begin{array}{l}\text { No CV benefit among the } 3 \text { arms; } \\
\text { proteinuria reduction in } \\
\text { combination therapy arm }\end{array}$ & $\begin{array}{l}\text { Increase in "DDT" } \\
\text { events in combination } \\
\text { therapy arm }\end{array}$ \\
\hline $\begin{array}{l}\text { VA } \\
\text { NEPRON-D }\end{array}$ & $\begin{array}{l}\text { T2DM and } \\
\text { proteinuria }\end{array}$ & 1448 & $\begin{array}{l}\text { Losartan and lisinopril } \\
\text { vs. losartan and placebo }\end{array}$ & $\begin{array}{l}\text { Trial terminated early due to AKI } \\
\text { events and hyperkalemia in } \\
\text { combination therapy arm }\end{array}$ & \\
\hline ALTITUDE & $\begin{array}{l}\text { T2DM, } \\
\text { proteinuria, and } \\
\text { CV risk }\end{array}$ & 8561 & $\begin{array}{l}\text { ACEi or ARB and } \\
\text { aliskiren vs. ACEi or } \\
\text { ARB and placebo }\end{array}$ & $\begin{array}{l}\text { Trial terminated early due to } \\
\text { increase in adverse events and no } \\
\text { apparent benefit in the } \\
\text { dual-therapy arm }\end{array}$ & \\
\hline
\end{tabular}

and Mortality in Type 2 Diabetes) and CANVAS (Canagliflozin Cardiovascular Assessment Study) demonstrated significant cardiovascular risk reduction when used for the treatment of diabetes [46] [47]. In these cardiovascular outcome trials, the SGLT2 inhibitors had positive effects on kidney outcomes, namely albuminuria reduction and a reduction in the occurrence of a composite renal outcome. In the EMPA-REG Outcome trial, the HR in the empagliflozin arm for incident or worsening nephropathy (a composite of the development of albuminuria with albumin excretion $>300 \mathrm{mg} / \mathrm{g}$ creatinine, doubling of serum creatinine accompanied by eGFR $\leq 45 \mathrm{~mL} / \mathrm{min}$, initiation of renal replacement therapy, or death from renal causes) was $0.61(P<0.001)$ [46]. CANVAS demonstrated a benefit of similar magnitude (HR, 0.60$)$ on a composite outcome of a sustained $40 \%$ reduction in eGFR, need for renal replacement therapy, or death from renal causes [47]. Trials including CREDANCE (Evaluation of the Effects 
of Canagliflozin on Renal and Cardiovascular Outcomes in Participants with Diabetic Nephropathy) which studied canagliflozin and DAPA-CKD (A Study to Evaluate the Effect of Dapagliflozin on Renal Outcomes and Cardiovascular Mortality in Patients With Chronic Kidney Disease) which studied dapagliflozin, have since then confirmed the efficacy of SGLT2 inhibitors to slow the progression of diabetic nephropathy [48] [49].

\section{Conflicts of Interest}

The author declares no conflicts of interest regarding the publication of this paper.

\section{References}

[1] Afkarian, M., Zelnick, L.R., Hall, Y.N., Heagerty, P.J., Tuttle, K., Weiss, N.S. and de Boer, I.H. (2016) Clinical Manifestations of Kidney Disease among US Adults with Diabetes, 1988-2014. JAMA, 316, 602-610. https://doi.org/10.1001/jama.2016.10924

[2] Bakris, G.L. (2019) Major Advancements in Slowing Diabetic Kidney Disease Progression: Focus on SGLT2 Inhibitors. American Journal of Kidney Diseases, 74, 573-575. https://doi.org/10.1053/j.ajkd.2019.05.009

[3] Choi, A.I., Weekley, C.C., Chen, S.C., Li, S., Kurella Tamura, M., Norris, K.C. and Shlipak, M.G. (2011) Association of Educational Attainment with Chronic Disease and Mortality: The Kidney Early Evaluation Program (KEEP). American Journal of Kidney Diseases, 58, 228-234. https://doi.org/10.1053/j.ajkd.2011.02.388

[4] Kruzel-Davila, E., Wasser, W.G., Aviram, S. and Skorecki, K. (2016) APOL1 Nephropathy: From Gene to Mechanisms of Kidney Injury. Nephrology Dialysis Transplantation, 31, 349-358. https://doi.org/10.1093/ndt/gfu391

[5] Nelson, R.G., Bennett, P.H., Beck, G.J., Tan, M., Knowler, W.C., Mitch, W.E., Hirschman, G.H. and Myers, B.D. (1996) Development and Progression of Renal Disease in Pima Indians with Non-Insulin-Dependent Diabetes Mellitus. The New England Journal of Medicine, 335, 1636-1642. https://doi.org/10.1056/NEJM199611283352203

[6] Bierhaus, A., Humpert, P.M., Morcos, M., Wendt, T., Chavakis, T., Arnold, B., Stern, D.M. and Nawroth, P.P. (2005) Understanding RAGE, the Receptor for Advanced Glycation End Products. Journal of Molecular Medicine, 83, 876-886. https://doi.org/10.1007/s00109-005-0688-7

[7] Tonneijck, L., Muskiet, M.H., Smits, M.M., van Bommel, E.J., Heerspink, H.J., van Raalte, D.H. and Joles, J.A. (2017) Glomerular Hyperfiltration in Diabetes: Mechanisms, Clinical Significance, and Treatment. Journal of the American Society of Nephrology, 28, 1023-1039. https://doi.org/10.1681/ASN.2016060666

[8] Helal, I., Fick-Brosnahan, G.M., Reed-Gitomer, B. and Schrier, R.W. (2012) Glomerular Hyperfiltration: Definitions, Mechanisms and Clinical Implications. Nature Reviews Nephrology, 8, 293-300. https://doi.org/10.1038/nrneph.2012.19

[9] Toth-Manikowski, S. and Atta, M.G. (2015) Diabetic Kidney Disease: Pathophysiology and Therapeutic Targets. Journal of Diabetes Research, 2015, Article ID: 697010. https://doi.org/10.1155/2015/697010

[10] Fioretto, P., Steffes, M.W., Sutherland, D.E. and Mauer, M. (1995) Sequential Renal Biopsies in Insulin-Dependent Diabetic Patients: Structural Factors Associated with Clinical Progression. Kidney International, 48, 1929-1935. 
https://doi.org/10.1038/ki.1995.493

[11] Kussman, M.J., Goldstein, H. and Gleason, R.E. (1976) The Clinical Course of Diabetic Nephropathy. JAMA, 236, 1861-1863.

https://doi.org/10.1001/jama.1976.03270170027020

[12] Hovind, P., Tarnow, L., Rossing, P., Jensen, B.R., Graae, M., Torp, I., Binder, C. and Parving, H.H. (2004) Predictors for the Development of Microalbuminuria and Macroalbuminuria in Patients with Type 1 Diabetes: Inception Cohort Study. BMJ, 328, Article No. 1105. https://doi.org/10.1136/bmj.38070.450891.FE

[13] Inker, L.A., Astor, B.C., Fox, C.H., Isakova, T., Lash, J.P. Peralta, C.A., Kurella Tamura, M. and Feldman, H.I. (2014) KDOQI US Commentary on the 2012 KDIGO Clinical Practice Guideline for the Evaluation and Management of CKD. American Journal of Kidney Diseases, 63, 713-735. https://doi.org/10.1053/j.ajkd.2014.01.416

[14] Packham, D.K., Alves, T.P., Dwyer, J.P., Atkins, R., de Zeeuw, D., Cooper, M., Shahinfar, S., Lewis, J.B. and Lambers Heerspink, H.J. (2012) Relative Incidence of ESRD versus Cardiovascular Mortality in Proteinuric Type 2 Diabetes and Nephropathy: Results from the DIAMETRIC (Diabetes Mellitus Treatment for Renal Insufficiency Consortium) Database. American Journal of Kidney Diseases, 59, 75-83. https://doi.org/10.1053/j.ajkd.2011.09.017

[15] Eijkelkamp, W.B., Zhang, Z., Remuzzi, G., Parving, H.H., Cooper, M.E., Keane, W.F., Shahinfar, S., Gleim, G.W., Weir, M.R., Brenner, B.M., et al. (2007) Albuminuria Is a Target for Renoprotective Therapy Independent from Blood Pressure in Patients with Type 2 Diabetic Nephropathy: Post Hoc Analysis from the Reduction of Endpoints in NIDDM with the Angiotensin II Antagonist Losartan (RENAAL) trial. Journal of the American Society of Nephrology, 18, 1540-1546.

https://doi.org/10.1681/ASN.2006050445

[16] Dwyer, J.P. and Lewis, J.B. (2013) Nonproteinuric Diabetic Nephropathy: When Diabetics Don't Read the Textbook. Medical Clinics of North America, 97, 53-58. https://doi.org/10.1016/j.mcna.2012.10.006

[17] National Kidney Foundation (2012) KDOQI Clinical Practice Guideline for Diabetes and CKD: 2012 Update. American Journal of Kidney Diseases, 60, 850-886. https://doi.org/10.1053/j.ajkd.2012.07.005

[18] Orchard, T.J., Dorman, J.S., Maser, R.E., Becker, D.J., Drash, A.L., Ellis, D., LaPorte, R.E. and Kuller, L.H. (1990) Prevalence of Complications in IDDM by Sex and Duration. Pittsburgh Epidemiology of Diabetes Complications Study II. Diabetes, 39, 1116-1124. https://doi.org/10.2337/diab.39.9.1116

[19] Schwartz, M.M., Lewis, E.J., Leonard-Martin, T., Lewis, J.B. and Batlle, D. (1998) Renal Pathology Patterns in Type II Diabetes Mellitus: Relationship with Retinopathy. Nephrology Dialysis Transplantation, 13, 2547-2552.

https://doi.org/10.1093/ndt/13.10.2547

[20] Fioretto, P., Mauer, M., Brocco, E., Velussi, M., Frigato, F., Muollo, B., Sambataro, M., Abaterusso, C., Baggio, B., Crepaldi, G., et al. (1996) Patterns of Renal Injury in NIDDM Patients with Microalbuminuria. Diabetologia, 39, 1569-1576.

https://doi.org/10.1007/s001250050616

[21] Selby, N.M. and Taal, M.W. (2019) Long-Term Outcomes after AKI-A Major Unmet Clinical Need. Kidney International, 95, 21-23. https://doi.org/10.1016/j.kint.2018.09.005

[22] Yu, S.M. and Bonventre, J.V. (2018) Acute Kidney Injury and Progression of Diabetic Kidney Disease. Advances in Chronic Kidney Disease, 25, 166-180. https://doi.org/10.1053/j.ackd.2017.12.005 
[23] Jiang, S., Wang, Y., Zhang, Z., Dai, P., Yang, Y. and Li, W. (2018) Accuracy of Hematuria for Predicting Non-Diabetic Renal Disease in Patients with Diabetes and Kidney Disease: A Systematic Review and Meta-Analysis. Diabetes Research and Clinical Practice, 143, 288-300. https://doi.org/10.1016/j.diabres.2018.07.027

[24] Leung, N., Bridoux, F., Batuman, V., Chaidos, A., Cockwell, P., D’Agati, V.D., Dispenzieri, A., Fervenza, F.C., Fermand, J.P., Gibbs, S., et al. (2019) The Evaluation of Monoclonal Gammopathy of Renal Significance: A Consensus Report of the International Kidney and Monoclonal Gammopathy Research Group. Nature Reviews Nephrology, 15, 45-59. https://doi.org/10.1038/s41581-018-0077-4

[25] The Diabetes Control and Complications Trial Research Group (1993) The Effect of Intensive Treatment of Diabetes on the Development and Progression of Long-Term Complications in Insulin-Dependent Diabetes Mellitus. The New England Journal of Medicine, 329, 977-986. https://doi.org/10.1056/NEJM199309303291401

[26] The DCCT/EDIC Research Group (2011) Intensive Diabetes Therapy and Glomerular Filtration Rate in Type 1 Diabetes. The New England Journal of Medicine, 365, 2366-2376. https://doi.org/10.1056/NEJMoa1111732

[27] UK Prospective Diabetes Study (UKPDS) Group (1998) Intensive Blood-Glucose Control with Sulphonylureas or Insulin Compared with Conventional Treatment and Risk of Complications in Patients with Type 2 Diabetes (UKPDS 33). Lancet, 352, 837-853. https://doi.org/10.1016/S0140-6736(98)07019-6

[28] The ADVANCE Collaborative Group (2008) Intensive Blood Glucose Control and Vascular Outcomes in Patients with Type 2 Diabetes. The New England Journal of Medicine, 358, 2560-2572. https://doi.org/10.1056/NEJMoa0802987

[29] The Action to Control Cardiovascular Risk in Diabetes Study Group (2008) Effects of Intensive Glucose Lowering in Type 2 Diabetes. The New England Journal of Medicine, 358, 2545-2559. https://doi.org/10.1056/NEJMoa0802743

[30] Duckworth, W., Abraira, C., Moritz, T., Reda, D., Emanuele, N., Reaven, P.D., Zieve, F.J., Marks, J., Davis, S.N., Hayward, R., et al. (2009) Glucose Control and Vascular Complications in Veterans with Type 2 Diabetes. The New England Journal of Medicine, 360, 129-139. https://doi.org/10.1056/NEJMoa0808431

[31] de Galan, B.E., Perkovic, V., Ninomiya, T., Pillai, A., Patel, A., Cass, A., Neal, B, Poulter, N., Harrap, S., Mogensen, C.E., et al. (2009) Lowering Blood Pressure Reduces Renal Events in Type 2 Diabetes. Journal of the American Society of Nephrology, 20, 883-892. https://doi.org/10.1681/ASN.2008070667

[32] UK Prospective Diabetes Study Group (1998) Tight Blood Pressure Control and Risk of Macrovascular and Microvascular Complications in Type 2 diabetes: UKPDS 38. BMJ, 317, 703-713. https://doi.org/10.1136/bmj.317.7160.703

[33] Schrier, R.W., Estacio, R., Mehler, P.S. and Hiatt, W.R. (2007) Appropriate Blood Pressure Control in Hypertensive and Normotensive Type 2 Diabetes Mellitus: A Summary of the ABCD Trial. Nature Clinical Practice Nephrology, 3, 428-438. https://doi.org/10.1038/ncpneph0559

[34] The ACCORD Study Group (2010) Effects of Intensive Blood-Pressure Control in Type 2 Diabetes Mellitus. The New England Journal of Medicine, 362, 1575-1585. https://doi.org/10.1056/NEJMoa1001286

[35] Schrier, R.W., Estacio, R.O., Esler, A. and Mehler, P. (2002) Effects of Aggressive Blood Pressure Control in Normotensive Type 2 Diabetic Patients on Albuminuria, Retinopathy and Strokes. Kidney International, 61, 1086-1097. https://doi.org/10.1046/j.1523-1755.2002.00213.x

[36] Arnett, D.K., Blumenthal, R.S., Albert, M.A., Buroker, A.B., Goldberger, Z.D., Hahn, 
E.J., Himmelfarb, C.D., Khera, A., Lloyd-Jones, D., McEvoy, J.W., et al. (2019) 2019 ACC/AHA Guideline on the Primary Prevention of Cardiovascular Disease: A Report of the American College of Cardiology/American Heart Association Task Force on Clinical Practice Guidelines. Circulation, 140, e596-e646. https://doi.org/10.1161/CIR.0000000000000678

[37] Ritz, E., Menne, J. and Haller, H. (2012) Prevalence of Microalbuminuria in Type 2 Diabetes: Lessons Learned from the ROADMAP Study. Nephrology Dialysis Transplantation, 27, iv28-iv30. https://doi.org/10.1093/ndt/gfs424

[38] Parving, H.H., Lehnert, H., Brochner-Mortensen, J., Gomis, R., Andersen, S. and Arner, P. (2001) The Effect of Irbesartan on the Development of Diabetic Nephropathy in Patients with Type 2 Diabetes. The New England Journal of Medicine, 345, 870-878. https://doi.org/10.1056/NEJMoa011489

[39] Lewis, E.J., Hunsicker, L.G., Bain, R.P. and Rohde, R.D. (1993) The Effect of Angiotensin-Converting-Enzyme Inhibition on Diabetic Nephropathy. The New England Journal of Medicine, 329, 1456-1462. https://doi.org/10.1056/NEJM199311113292004

[40] Brenner, B.M., Cooper, M.E., de Zeeuw, D., Keane, W.F., Mitch, W.E., Parving, H.H., Remuzzi, G., Snapinn, S.M., Zhang, Z., Shahinfar, S., et al. (2001) Effects of Losartan on Renal and Cardiovascular Outcomes in Patients with Type 2 Diabetes and Nephropathy. The New England Journal of Medicine, 345, 861-869.

https://doi.org/10.1056/NEJMoa011161

[41] Lewis, E.J., Hunsicker, L.G., Clarke, W.R., Berl, T., Pohl, M.A., Lewis, J.B., Ritz, E., Atkins, R.C., Rohde, R., Raz, I., et al. (2001) Renoprotective Effect of the Angiotensin-Receptor Antagonist Irbesartan in Patients With Nephropathy Due to Type 2 Diabetes. The New England Journal of Medicine, 345, 851-860. https://doi.org/10.1056/NEJMoa011303

[42] Mann, J.F., Schmieder, R.E., McQueen, M., Dyal, L., Schumacher, H., Pogue, J., Wang, X., Maggioni, A., Budaj, A., Chaithiraphan, S. et al. (2008) Renal Outcomes with Telmisartan, Ramipril, or Both, in People at High Vascular Risk (the ONTARGET Study): A Multicentre, Randomised, Double-Blind, Controlled Trial. Lancet, 372, 547-553. https://doi.org/10.1016/S0140-6736(08)61236-2

[43] Fried, L.F., Emanuele, N., Zhang, J.H., Brophy, M., Conner, T.A., Duckworth, W., Leehey, D.J., McCullough, P.A., O’Connor, T., Palevsky, P.M., et al. (2013) Combined Angiotensin Inhibition for the Treatment of Diabetic Nephropathy. The New England Journal of Medicine, 369, 1892-1903.

https://doi.org/10.1056/NEJMoa1303154

[44] Jhund, P.S., McMurray, J.J., Chaturvedi, N., Brunel, P., Desai, A.S., Finn, P.V., Haffner, S.M., Solomon, S.D., Weinrauch, L.A., Claggett, B.L., et al. (2015) Mortality Following a Cardiovascular or Renal Event in Patients with Type 2 Diabetes in the Altitude Trial. European Heart Journal, 36, 2463-2469. https://doi.org/10.1093/eurheartj/ehv295

[45] Heerspink, H.J., Perkins, B.A., Fitchett, D.H., Husain, M. and Cherney, D.Z. (2016) Sodium Glucose Cotransporter 2 Inhibitors in the Treatment of Diabetes Mellitus: Cardiovascular and Kidney Effects, Potential Mechanisms, and Clinical Applications. Circulation, 134, 752-772. https://doi.org/10.1161/CIRCULATIONAHA.116.021887

[46] Zinman, B., Wanner, C., Lachin, J.M., Fitchett, D., Bluhmki, E., Hantel, S., Mattheus, M., Devins, T., Johansen, O.E., Woerle, H.J., et al. (2015) Empagliflozin, Cardiovascular Outcomes, and Mortality in Type 2 Diabetes. The New England Journal of Medicine, 373, 2117-2128. https://doi.org/10.1056/NEJMoa1504720 
[47] Neal, B., Perkovic, V., Mahaffey, K.W., de Zeeuw, D., Fulcher, G., Erondu, N., Shaw, W., Law, G., Desai, M., Matthews, D.R., et al. (2017) Canagliflozin and Cardiovascular and Renal Events in Type 2 Diabetes. The New England Journal of Medicine, 377, 644-657. https://doi.org/10.1056/NEJMoa1611925

[48] Heerspink, H.J.L., Stefansson, B.V., Correa-Rotter, R., Chertow, G.M., Greene, T., Hou, F.F., Mann, J.F.E., McMurray, J.J.V., Lindberg, M., Rossing, P., et al. (2020) Dapagliflozin in Patients with Chronic Kidney Disease. The New England Journal of Medicine, 383, 1436-1446. https://doi.org/10.1056/NEJMoa2024816

[49] Perkovic, V., Jardine, M.J., Neal, B., Bompoint, S., Heerspink, H.J.L., Charytan, D.M., Edwards, R., Agarwal, R., Bakris, G., Bull, S., et al. (2019) Canagliflozin and Renal Outcomes in Type 2 Diabetes and Nephropathy. The New England Journal of medicine, 380, 2295-2306. https://doi.org/10.1056/NEJMoa1811744 